\title{
Function of the anal sphincters in spinal man
}

\author{
B. FRENCKNER
}

From the Department of Clinical Physiology, Serafimer Hospital, Stockholm, Sweden

SUMMARY Eight patients with traumatic transverse lesions of the spinal cord and eight healthy controls were examined with respect to the function of the anal sphincters. Continuous recordings of anal pressure and electromyograms from the striated sphincter muscles were obtained during gradual rectal distension by means of an air-filled balloon. The patients were more prone than the controls to display a cessation of all electrical activity from the striated muscles in response to rectal distension and they also exhibited a less pronounced inflation reflex.

It is concluded that upon rectal distension in normal man the striated muscles are stimulated by a cerebral centre at an unconscious level as well as by a low centre of the spinal cord. The former accounts for an augmented inflation reflex and maintained or increased electrical activity when rectal distension is substantial. The smooth internal sphincter was found to be independent of cerebral influence at rest as well as during rectal distension.

Anal continence is normally maintained by the anal sphincter muscles which surround the anal canal. They are divided into the smooth internal sphincter, which is the distal part of the enteric muscular coat, and the striated sphincter muscles, namely, the external sphincter and the puborectalis muscle. The pressure of the anal canal at rest is due mainly to activity of the internal sphincter (Duthie and Watts, 1965; Frenckner and v. Euler, 1975) but the external sphincter also maintains a constant tonic activity (Floyd and Walls, 1953). When the rectum is moderately distended the internal sphincter is transiently relaxed (Gowers, 1877; Denny-Brown and Robertson, 1935) and further distension results in a constant relaxation, ie, the tone of the internal sphincter does not return to its original level but becomes progressively smaller (Gaston, 1948; Kerremans, 1969; Ihre, 1974). The relaxation reflex seems to be mediated via local nerve plexuses, as it occurs in patients with damage to the sacral nerve roots, flaccid paraplegia (Gowers, 1877; DennyBrown and Robertson, 1935) and in children with myelomeningocele (Varma and Stephens, 1972). However, it is still unclear to what extent this reflex is affected quantitatively by cerebral impulses.

Rectal distension also elicits a contraction of the striated muscles (Gaston, 1948; Goligher and Hughes, 1951), a response which has been called the 'inflation reflex' (Ihre, 1974). This reflex, as well as the tonic activity of the striated muscles, is present

Received for publication 3 June 1975. in patients with transverse lesions of the spinal cord. They are therefore held to be regulated in part via a low centre of the spinal cord (Parks, Porter, and Melzak, 1962; Porter, 1962; Melzak and Porter, 1964), but is is still not known to what extent the reflex activity of the striated muscles is influenced by cerebral reflexes.

The aim of this study was to evaluate the involuntary cerebral influence on the smooth internal sphincter as well as on the striated sphincter muscles. For this purpose, patients with transverse lesions of the spinal cord were studied and the results were compared with those of normal subjects.

\section{Material and Methods}

\section{SUBJECTS}

Eight male patients aged 26 to 54 years (mean 35) with traumatic transverse lesions of the spinal cord, six complete and two incomplete (nos. 7 and 8),

\begin{tabular}{lllll}
\hline No. & Age & $\begin{array}{c}\text { Time in } \\
\text { Years after } \\
\text { Injury }\end{array}$ & $\begin{array}{l}\text { Level of } \\
\text { Injury }\end{array}$ & Notes \\
\hline 1 & 36 & 5 & Th IV & \\
2 & 26 & 7 & Th X & \\
3 & 34 & 4 & Th XI & \\
4 & 33 & 10 & C VI & \\
5 & 54 & 8 & Th VII & \\
6 & 37 & 2 & Th IV & Incomplete \\
7 & 29 & 2 & L I & Incomplete \\
8 & 34 & 10 & Th XII & \\
\hline Table & Clinical data for patient group &
\end{tabular}


were examined (table I). The level of the lesions was determined by examination of the dermatomes, which observations were correlated to the $x$-ray findings of the spinal column. The level was found to vary between C VI and L I. Most of the patients exhibited regular bowel habits and were fairly continent with respect to solid faeces. None of the patients had any history of anorectal disorders, diarrhoea or constipation before the accident, except that two (nos. 6 and 8) had suffered from minor internal haemorrhoids.

The results in these patients were compared with those in eight healthy male volunteers aged 20 to 60 years (mean 36), likewise with no history of anorectal disorders, diarrhoea or constipation. The patients and control subjects were informed of the nature, purpose and possible risks of the study before giving their consent to participate.

\section{PROCEDURE}

The examinations were performed in the afternoon, the subject having defaecated in the morning or the day before. The subject was placed in the left supine position with the hips flexed $90^{\circ}$. The anus was inspected before introducing the water-filled balloon to measure the pressure in the anal canal. This instrument (fig 1) consists of a metal cylinder fitted with a latex balloon. It was connected via a pressure transducer (EMT 34, Siemens-Elema) to an amplifier (EMT 31, Siemens-Elema) and an ink-jet recorder (Mingograph 42B, Siemens-Elema). The anal pressure was measured at distances of $1,2,3$ and $4 \mathrm{~cm}$ from the anal verge in order to locate the zone of maximal anal pressure. When this had been done, the instrument was withdrawn and a digital examination was undertaken of ampulla recti and the anal canal. Having carefully located the puborectalis muscle, the investigator inserted a concentric needle electrode $45 \mathrm{~mm}$ long into this muscle via the skin of the crena ani 1 to $2 \mathrm{~cm}$ dorsal of the anus. Using a proctoscope, a latex balloon was then placed in the ampulla 6-8 $\mathrm{cm}$ above the anus. This balloon, which measured about $3 \times 1.5 \mathrm{~cm}$ when empty, was connected to a polyethylene tube about $75 \mathrm{~cm}$ long with an internal diameter of $2 \mathrm{~mm}$ and an external of $2.2 \mathrm{~mm}$. When the proctoscope had been re-

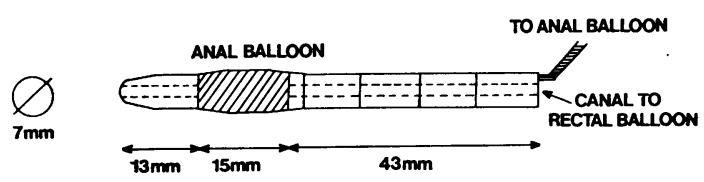

Fig 1 Diagrammatic drawing of the device for measuring pressure in the anal canal. It consists of a metal cylinder fitted with a latex balloon. moved, the balloon was inflated with $50 \mathrm{ml}$ of air (which was immediately evacuated) in order to ensure that it lay unfolded. The polyethylene tube was connected via a three-way stopcock to a 50-ml glass syringe and an electric pressure transducer (EMT 34), which led in turn after amplification (EMT 31) to the Mingograph recorder. Finally a concentric needle electrode $21 \mathrm{~mm}$ long was inserted into the external sphincter via the skin 0.5 to $1 \mathrm{~cm}$ directly to the left of the anus. After amplification (Grass, models P9A), the signals from the two EMG electrodes were recorded directly (Mingograph 42B) and also, in the case of the signal from the external sphincter, after integration (time constant $0.3 \mathrm{sec}$; integrator EMT 43B, Siemens-Elema).

A brief recording was obtained of the muscle activity at rest and the anal reflex was tested by cautiously drawing the tip of a needle across the perianal skin. Before the rectal balloon was filled with air, the subject was instructed to tell the investigator as soon as he experienced a slight feeling in the rectum and then, as filling proceeded, when the feeling became so pronounced that he would normally have gone to the lavatory; the later stage will be referred to as a substantial filling of the rectum. After these instructions, the balloon was inflated with air, starting with $20 \mathrm{ml}$, then $30 \mathrm{ml}$ and then portions of $50 \mathrm{ml}$, with an interval of 30 seconds between each portion. It took approximately 0.7$0.9 \mathrm{sec}$ to fill each portion. Filling was stopped either when the balloon was automatically defaecated, or when the subject was unable to tolerate any further expansion of the rectum (maximal tolerable volume), or when the balloon had been filled to capacity $(500 \mathrm{ml})$. Some minutes after the rectal balloon had been evacuated, the water-filled anal balloon was reintroduced so that it lay in the zone of the maximal anal pressure. As this instrument has a hole down its centre, it could be introduced with the polyethylene tube to the rectal balloon running through it. The anal balloon was linked up as before to the recorder. A few minutes later, when the anal pressure had stabilized, the rectal balloon was again filled by stages as above and this was stopped when there was a constant relaxation of the anal pressure, whereupon the rectal balloon was evacuated. Finally a check was made to ensure that the anal balloon had not shifted.

When the experiment had been performed, the rectal balloon was refilled with air in stages $(20$, $50,100 \mathrm{ml}$ etc) in the surrounding air in order to measure the pressure which the balloon itself generated at different volumes. These pressures were then subtracted from those measured earlier in the rectum during the first series in order to obtain corrected values for the pressure which the rectum 
exerted on the balloon (Ihre, 1974). The general procedure has been used earlier (Frenckner and v. Euler, 1975) and resembles that described by Ihre (1974).

\section{STATISTICS}

Standard statistical methods have been employed using the $t$ test when applicable. The non-parametric median test (Dixon and Massey, 1957) was used in cases when a normal distribution could not be expected. In one case the $\chi^{2}$ test of independence (Dixon and Massey, 1957) was used. Data in the text and figures are given as mean $\pm \mathrm{SE}$ (standard error of the mean).

\section{Results}

\section{SUBJECTIVE PERCEPTIONS AND RECTAL}

PRESSURE

Six of the patients did not feel the rectal balloon at all. One (no. 7) reported a slight feeling of filling when the balloon was expanded with $50 \mathrm{ml}$ of air and one (no. 8) when it was expanded with $100 \mathrm{ml}$. The controls reported this first slight feeling of rectal distension at an average rectal volume of $55 \mathrm{ml}$ (range 20-100 $\mathrm{ml}$ ) and a substantial distension at an average of $220 \mathrm{ml}$ (range 100-350). The mean maximal tolerable volume was $400 \mathrm{ml}$ (range 300500).

In all patients but one (no. 4) the rectal balloon was defaecated autonomously while distended (average volume $270 \mathrm{ml}$, range 150-400) but this

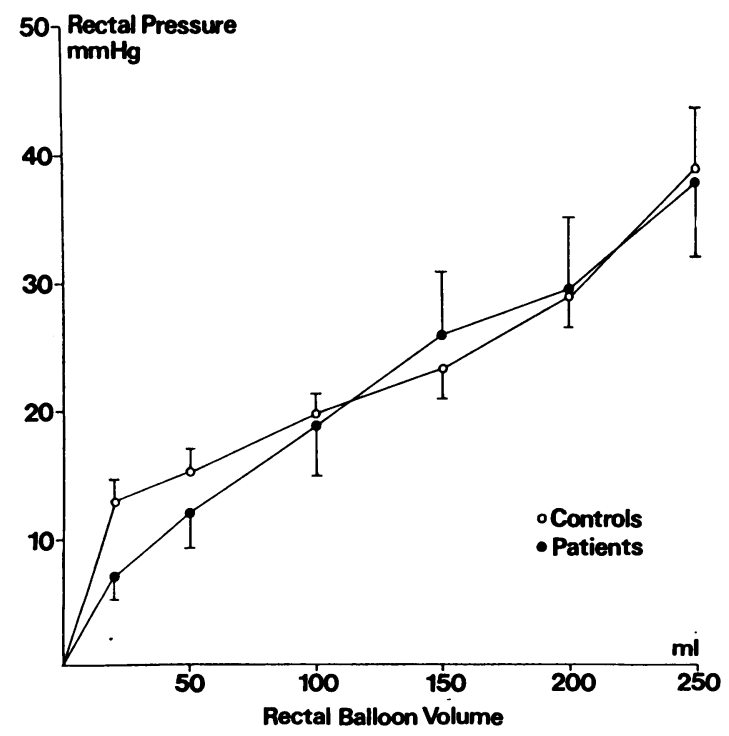

Fig 2 Corrected rectal pressures at different volumes of the rectal balloon. There is obviously no difference between patients and controls. did not happen in any of the controls $(P<0.05$ by $\chi^{2}$ test).

The corrected rectal pressures at various volumes of the rectum were similar for patients and controls (fig 2). It is thus clear that rectal compliance did not differ between the two groups.

\section{ACTIVITY OF THE STRIATED SPHINCTER MUSCLES}

All patients and controls showed continuous tonic EMG activity of the external sphincter and the puborectalis muscle (figs 3 and 4) and the anal reflex was also positive in all cases. In one patient (no. 3 ) in whom a proper EMG recording was obtained with a high speed ultraviolet recording unit, there were normal action potentials and no signs of denervation. All the controls were able to perform strong voluntary contractions of the striated sphincter muscles and one of the patients (no. 8) was able to perform a slight voluntary contraction, but this was not the case in the other seven patients.

While the rectum was expanded, inflation reflexes of the striated muscles were recorded in all patients but two (nos. 5 and 6) and in all of the controls (fig 4). The rectal volumes at which the first inflation reflex was seen were significantly higher among the patients $(P<0.05$, median test).

When the rectum was further distended, the electrical activity of the striated muscles displayed one of two types. Either it gradually decreased and ultimately ceased altogether (fig 3) or it was unchanged or increased as long as the rectal filling proceeded (fig 4). The former type was seen in all patients but one (no. 4) but in only two of the controls. The remaining patient and controls showed the latter type. The rectal volumes at which electrical activity was lost were significantly smaller among the patients $(P<0.05$, median test; the volume was taken to be higher than the maximal rectal distension in those cases in which no loss of electrical activity was observed).

ANAL PRESSURE

When the anal balloon was again placed in the anal canal in the zone of maximal anal pressure after the first gradual expansion of the rectum, the pressure showed a considerable initial rise due to an anal reflex of the striated muscles but a few minutes later it had fallen and then remained fairly constant (maximal anal pressure). In five patients and five controls this pressure displayed a cyclic activity, the waves occurring at an average frequency of $64 \mathrm{c} / \mathrm{min}$. An earlier study showed that these waves are synchronous with the ECG, suggesting that they are a pulse artefact (Frenckner and v. Euler, 1975). The maximal anal pressure averaged $60 \pm 7.8 \mathrm{mmHg}$ 
EXTEANAL SPHINCTER

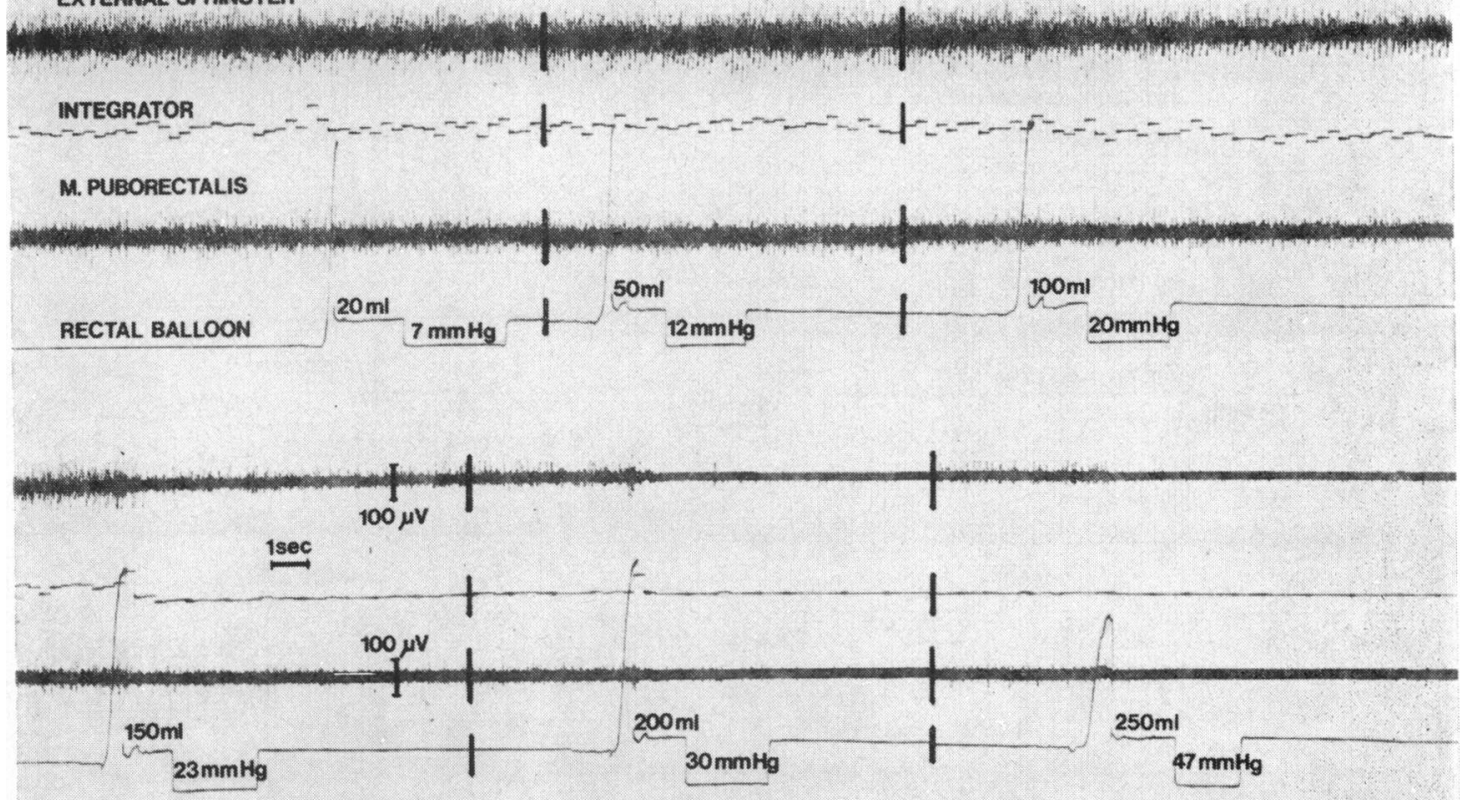

Fig 3 Electromyographic recordings from the striated sphincter muscles during the first rectal expansion in one of the patients. Rectal distension involves a decrease and ultimately a complete loss of electrical activity.

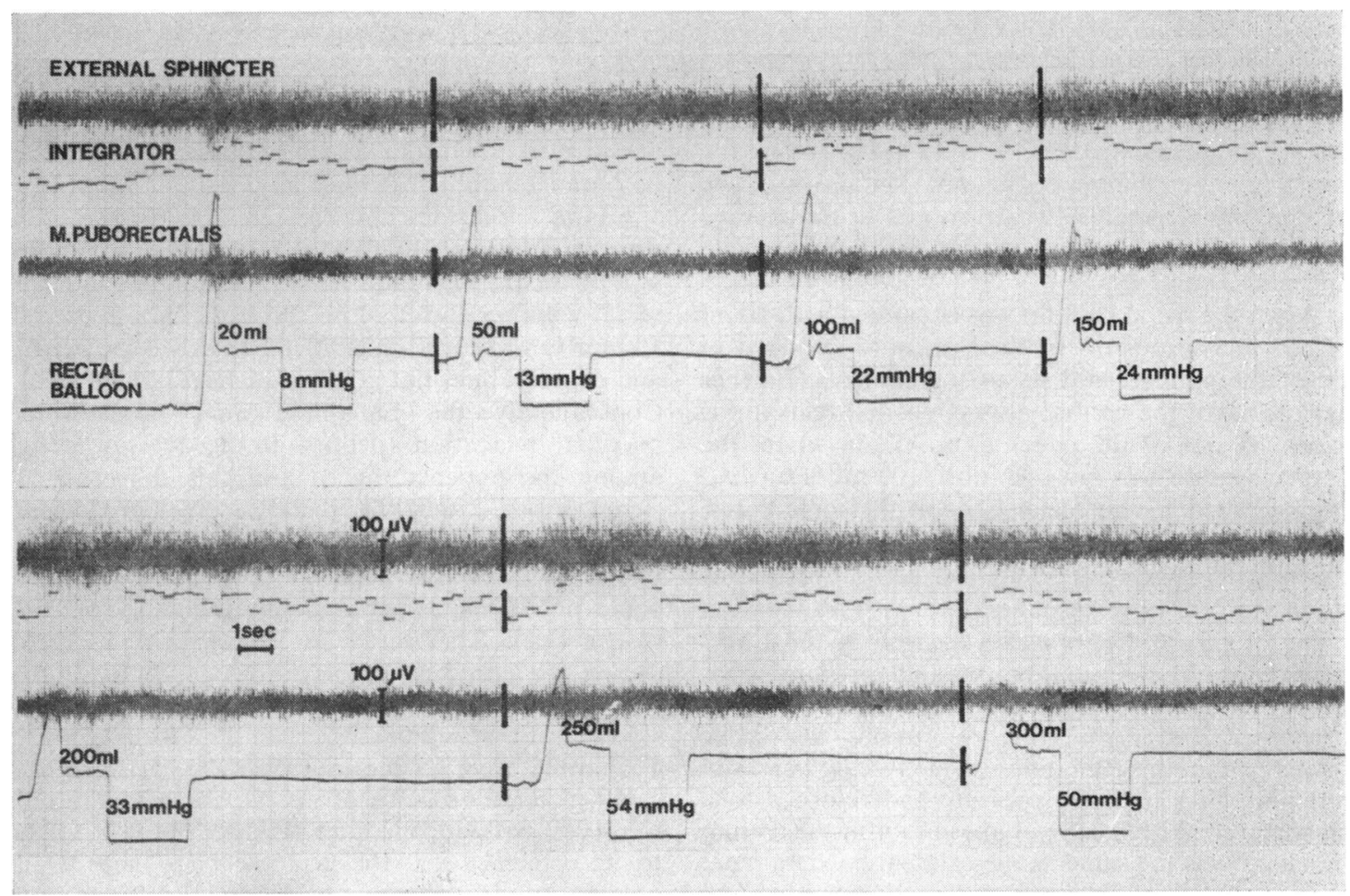

Fig 4 As fig 3 but in a control subject. Pronounced inflation reflexes and no decrease of electrical activity upon rectal distension. 


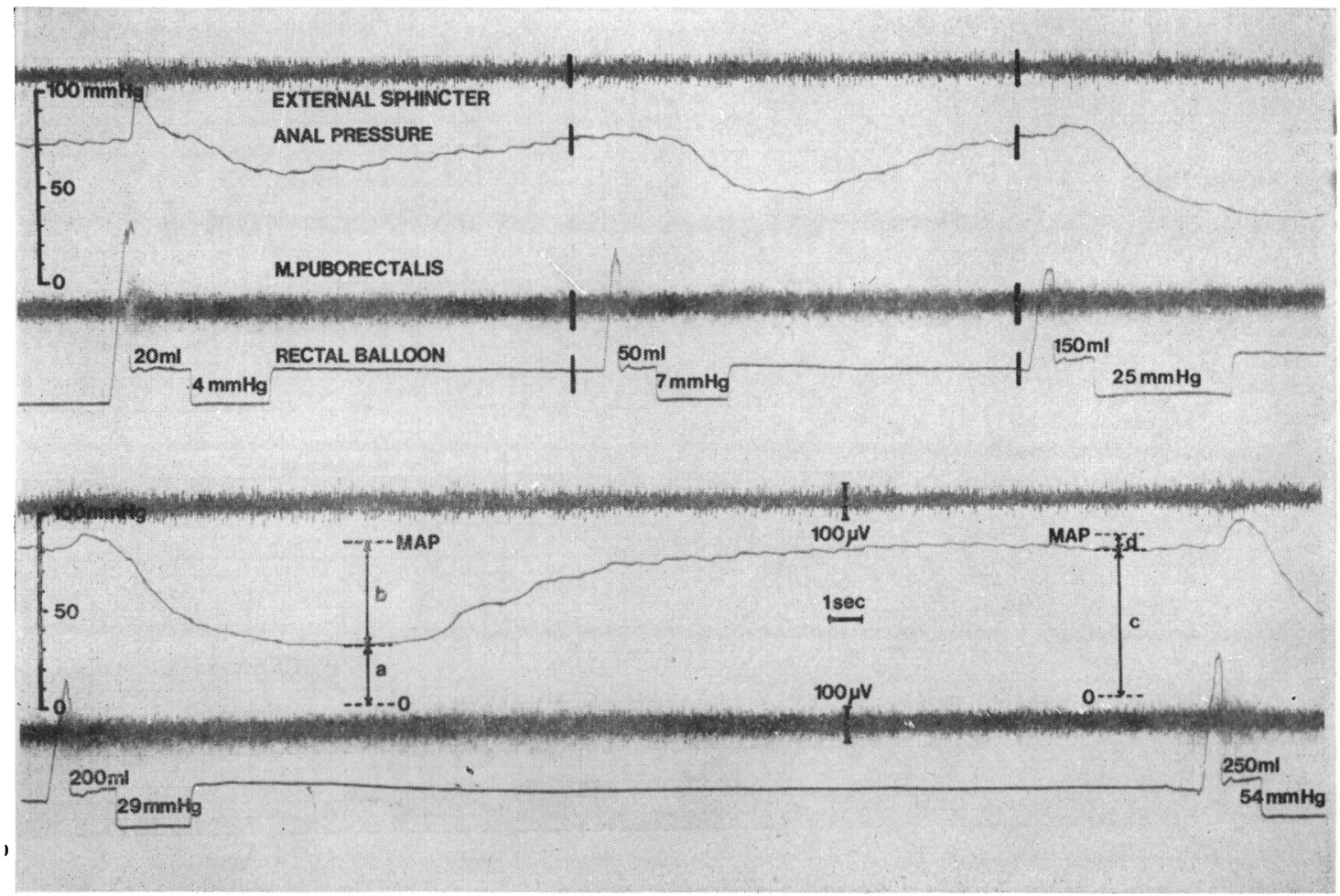

Fig 5 Recording of anal pressure in a control subject during the second rectal expansion, explaining the terms relaxation and constant relaxation: $\mathrm{a}=$ remaining pressure during relaxation, $\mathrm{b}=$ relaxation, $\mathrm{c}=$ remaining pressure during constant relaxation, and $\mathrm{d}=$ constant relaxation.

among the patients and $67 \pm 5.7 \mathrm{mmHg}$ among the controls; the difference is not significant. The maximal anal pressure was recorded at an average of $1.5 \mathrm{~cm}$ from the anal verge both in the patients and in the controls.

When the rectal balloon was expanded with $20 \mathrm{ml}$ of air, relaxations of the anal pressure occurred in six of the patients and six of the controls. Further expansion of the rectum always elicited relaxations except in one of the patients (no. 5), in whom the first relaxation was not seen until $100 \mathrm{ml}$ of air had been inflated in the rectal balloon. In some cases, both among the patients and among the controls, the anal pressure rose briefly just before the relaxation, which always was associated with an inflation reflex of the striated muscles as seen in the EMG recordings. The relaxations of anal pressure were deeper and lasted longer as expansion of the rectum proceeded and during the relaxations the cyclic waves of anal pressure diminished or ceased and did not normalize until the pressure had returned to a stable level. With small volumes of air in the rectum this level was the same as the original maximal anal pressure, but on further rectal expansion the anal pressure returned to a somewhat lower level, which has been referred to earlier as constant relaxation.

Figure 5 indicates how the relaxations have been defined. They were on the average more pronounced among the patients than among the controls and for rectal volumes above $50 \mathrm{ml}$ this difference averaged $10 \mathrm{mmHg}$; however, this difference between patients and controls does not attain statistical significances. Consequently the remaining anal pressure at maximal relaxation (defined in fig 5) was lower among the patients (fig 6) and this difference is significant $(P<0.05)$ for rectal volumes of 100 and $150 \mathrm{ml}$. This comparison, however, is complicated by the fact that the rectal balloon in the patients could not be expanded as much as in the controls (see above). Therefore the lowest anal pressure during the consecutive relaxations in each subject was measured and the average was found to be significantly $(P<0.05)$ lower for the patients $(16 \pm$ $1.7 \mathrm{mmHg})$ than for the controls $(28 \pm 5.1 \mathrm{mmHg})$.

When large volumes of air had been inflated in the rectal balloon, the anal pressure did not return to its original level, the decrease being somewhat greater among the patients. Consequently, the re- 


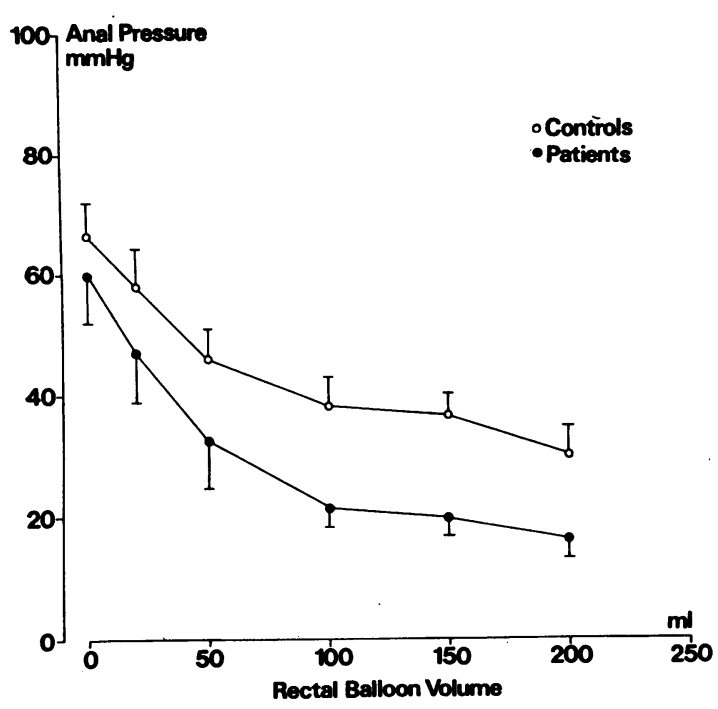

Fig 6 Remaining anal pressure at maximal relaxation (a in fig 5) among patients and controls at different volumes of the rectal balloon.

maining anal pressure, when this had returned to a stable value after a relaxation ( $c$ in fig 5) was lower among the patients than among the controls, but this difference is not significant. The average of the lowest value in each patient $(27 \pm 4 \cdot 1 \mathrm{mmHg})$ was lower than the corresponding average in the controls $(43 \pm 6.1 \mathrm{mmHg})$ but the difference is not fully significant $(P=0.054)$.

\section{Discussion}

Each subject was examined by a two-step procedure. First the rectum was expanded while only the thin polyethylene tube to the rectal balloon passed through the anal canal and during this step the activity of the striated sphincter muscles was evaluated; then another gradual expansion was produced while the device for detecting the anal pressure was also in the anal canal. This procedure was adopted because earlier experiments (Duthie and Watts, 1965) have suggested that a bolus in the anal canal may act as a stimulus for the striated sphincter muscles. This was also borne in mind when constructing the pressure-detecting device.

Great care was taken to ensure that the nerve lesions in the patients studied were exclusively central, so that the peripheral nerves and distal spinal reflex arcs were intact. That this was the case is indicated by the fact that all subjects had a readily palpable puborectalis sling without noticeable atrophy, tonic EMG activity from the striated muscles and a positive anal reflex. As a further check, a more extensive EMG examination was performed in one of the patients. No signs of peripheral nerve damage or denervation were observed. The differences found between the patients with transverse spinal lesions and the controls can thus be attributed to the interrupted nervous connexions from higher cerebral centres to the distal part of the spinal cord.

In this investigation, most of the patients displayed contraction of the striated sphincter muscles when the rectal ampulla was expanded, thereby confirming that this reflex (inflation reflex) is mediated via a spinal reflex arc, as has been demonstrated in earlier investigations (Parks et al, 1962; Porter, 1962; Melzak and Porter, 1964). But as this inflation reflex occurred more frequently and at lower rectal volumes among the controls, it must also be influenced by cerebral nerve centres and probably at an unconscious level, as the response was independent of whether or not the control subjects were told to relax completely.

When the rectal ampulla was gradually expanded, the type of electrical activity of the striated sphincter muscles differed between the patients and the controls. There was a loss of all electrical activity more often and at lower rectal volumes among the patients; this must be due to the interrupted cerebral connexions in view of the anatomical differences between the two groups. These findings in the patients are in accordance with those of Parks et al (1962) and Porter (1962), who reported a complete loss of all electrical activity when the rectal ampulla was expanded more than $150 \mathrm{ml}$. In contrast to the present results, they stated that the same applies in healthy subjects. Ihre (1974) reported loss of all electrical activity in nine out of 18 healthy subjects, at an average rectal volume of $382 \mathrm{ml}$, which supports the present findings. It therefore seems that the constant tonic activity and, in part, the inflation reflex of the striated sphincter muscles are regulated via a low centre of the spinal cord, which continues to function when the cord has been transected at higher levels. This tonic activity is totally inhibited when the rectum is distended. The muscles in healthy individuals, however, are also influenced by a cerebral centre at a subconscious level, which accentuates the inflation reflex and is responsible for the sustained and sometimes increased activity of the striated muscles when the rectum is distended moderately.

Anal pressure did not differ between the patients and the controls, which confirms earlier investigations (Denny-Brown and Robertson, 1935; Varma and Stephens, 1972). This strongly suggests that the activity of the internal sphincter at rest is independent 
of cerebral nervous connexions, as the anal pressure at rest is due almost completely to action of the internal sphincter (Frenckner and v. Euler, 1975). During rectal filling the well documented relaxation of the anal pressure was observed both among the patients and the controls and this was seen at the same rectal volumes as reported earlier (Schuster, Hookman, Hendrix, and Mendeloff, 1965; Kerremans, 1969; Ihre, 1974). The relaxations were, however, deeper among the patients, so that the remaining anal pressure just after a sudden substantial rectal distension was somewhat lower. When the rectum is distended further, earlier investigations (Gaston, 1948; Kerremans, 1969; Ihre, 1974) have reported that the anal pressure does not return to its original value, stabilizing instead at a somewhat lower level. This has been attributed to a constant relaxation of the internal sphincter, and this was found among the patients as well as the controls in this study. The decrease in anal pressure was, however, more pronounced among the patients, the difference being almost significant. To sum up, the patients showed a normal anal pressure at rest and a more pronounced relaxation and constant relaxation of anal pressure upon distension of the rectum. The latter two findings are to be expected in view of the finding that the puborectalis muscle and external sphincter displayed less activity upon rectal distension among the patients. The response was in fact similar, though not quite as pronounced, as when the striated muscles were paralysed by pudendal block (Frenckner and v. Euler, 1975). It therefore seems reasonable to conclude that the function of the internal sphincter, even upon rectal distension, is independent of cerebral nervous connexions.

In seven out of eight patients the rectal balloon was defaecated autonomously but this did not happen in any of the controls. Theoretically the defaecations may be active, due to autonomous contraction of the rectum (in which case the reflex should be inhibited by cerebral influence), or it may reflect impaired function of the striated muscles. The latter possibility seems to be supported by the fact that the patient in whom defaecation did not occur was the one with strong activity of the striated muscles. On the other hand, autonomous defaecation is not seen when the puborectalis muscle and the external sphincter are paralysed by pudendal block (Frenckner and v. Euler, 1975) but then the rest of the levator muscles are still functional. The present findings are therefore interpreted to indicate that the autonomous defaecation is due to impaired function of the striated sphincters and levator muscles, but the problem is still somewhat unclear.

\section{References}

Denny-Brown, D., and Robertson, E. G. (1935). An investigation of the nervous control of defaecation. Brain, 58, 256-310.

Dixon, W. D., and Massey, F. J. (1957). Introduction to Statistical Analysis. McGraw-Hill, New York

Duthie, H. L., and Watts, J. M. (1965). Contribution of the external anal sphincter to the pressure zone in the anal canal. Gut, 6, 64-68.

Floyd, W. F., and Walls, E. W. (1953). Electromyography of the sphincter ani externus in man. J. Physiol., 122, 599-609.

Frenckner, B., and v. Euler, Chr. (1975). Influence of pudendal block on the function of the anal sphincters. Gut, 16, 482-489.

Gaston, E. A. (1948). The physiology of fecal continence. Surg. Gynec. Obstet., 87, 280-290.

Goligher, J. C., and Hughes, E. S. R. (1951). Sensibility of the rectum and colon. Lancet, 1, 543-548.

Gowers, W. R. (1877). The automatic action of the sphincter ani. Proc. Roy. Soc., London, 26, 77-84.

Ihre, T. (1974). Studies on anal function in continent and incontinent patients. Scand. J. Gastroent., Suppl. 25.

Kerremans, R. '(1969). IMorphological and Physiological Aspects of Anal Continence and Defaecation. Arscia Uitgaven, Brussels.

Melzak, J., and Porter, N. H. (1964). Studies of the reflex activity of the external sphincter ani in spinal man. Paraplegia, 1, 277-296.

Parks, A. G., Porter, N. H., and Melzak, J. (1962). Experimental study of the reflex mechanism controlling the muscles of the pelvic floor. Dis. Colon. Rect., 5, 407-414.

Porter, N. H. (1962). A physiological study of the pelvic floor in rectal prolapse. Ann. Roy. Coll. Surg., 31, 379-404.

Schuster, M. M., Hookman, P., Hendrix, T. R., and Mendeloff, A. I. (1965). Simultaneous manometric recording of internal and external anal sphincteric refiexes. Bull. Johns Hopkins Hosp., 116, 79-88.

Varma, 'K. ‘K., and Stephens, D. (1972). Neuromuscular reflexes of rectal continence. Aust. N.Z. J. Surg., 41, 263-272. 